Table 2. Advice received by carers on specific issues

\begin{tabular}{|c|c|c|}
\hline & $\begin{array}{l}\text { Old age } \\
\text { service }(n=12)\end{array}$ & $\begin{array}{l}\text { Other } \\
\text { service }(n=28)\end{array}$ \\
\hline $\begin{array}{l}\text { Enduring power of } \\
\text { attorney }\end{array}$ & $10(83 \%)$ & $6(21 \%)$ \\
\hline Benefit entitlement & $4(33 \%)$ & $4(14 \%)$ \\
\hline $\begin{array}{l}\text { Ability to work (where } \\
\text { applicable) }\end{array}$ & $3(100 \%)$ & $1(7 \%)$ \\
\hline $\begin{array}{l}\text { Ability to make a will } \\
\text { Fitness to drive (where } \\
\text { applicable) }\end{array}$ & $\begin{array}{l}6(50 \%) \\
4(80 \%)\end{array}$ & $\begin{array}{l}3(11 \%) \\
8(40 \%)\end{array}$ \\
\hline
\end{tabular}

seeing a consultant to obtaining a diagnosis (14), then poor information (13), lack of practical help (5), and medical staff being rude or dismissive (3).

\section{Comment}

The study is limited by the smaller sample size and older age of the old age psychiatry sample relative to the comparison group. Carers' views on local services may not be generalisable to other parts of the country. The findings are dependent on the accuracy of carers' memories of events, sometimes from many years ago, and may be biased by subsequent events. Only 48 cases of early-onset dementia could be identified in a catchment population of 500000 , considerably lower than current estimates (Alzheimer's Disease Society). The low numbers identified in this study suggests that many sufferers are not in contact with secondary care, which may in itself be indicative of the poor service provision available for early-onset dementia.

With these cautions, the results of this study support the view that old age psychiatry seems better able to provide for people with early-onset dementia, as evidenced by better diagnostic information, higher rates of referral to social services and more frequent advice on financial/ occupational issues such as benefits, enduring power of attorney and work.

Despite this, few sufferers and carers had access to old age psychiatry services, which may in part be due to unresolved conflicts about resources. The low levels of information and advice received by the comparison group, and the finding that delays in making a diagnosis are the key source of carer dissatisfaction, may both relate to the gradually emergent nature of the disorder. The lower index of suspicion in younger people, the prevalence of rarer causes and the frequently non-specific nature of the prodromal symptoms may result in long involvement with other services before a diagnosis is made. Sufferers and carers may then be reluctant to break existing relationships and may see referral to old age psychiatry as stigmatising.

\section{References}

ALZHEIMER'S DISEASE SOCIETY (1995) Services for Younger People with Dementia: A Report by the Alzheimer's Disease Society. London: Alzhelmer's Disease Society.

BALDWIN, R. C. (1994) Acquired cognitive impairment in the presenium. Psychiatric Bulletin, 18, 463-465.

SPERLINGER, D. \& FURST, M. (1994) The service experiences of people with pre-senile dementia: A study of carers in one London Borough. International Journal of Psychiatry, 9, 177-178.

*Hilary J. Husband, Clinical Psychologist, Norfolk Mental Health Care NHS Trust, School of Health Policy and Practice. University of East Anglia, Norwich NRA 7TJ; and Meera N. Shah, Assistant Psychologist, Rampton Hospital, Retford. Nottinghamshire

*Correspondence

\title{
Facilitating a staff support group on an oncology ward: some observations
}

\section{Charles Montgomery}

Aims and method In this paper an experience of facilltating a weekly support group for nursing staff on an oncology ward is described. A brief overview of burnout among oncology nurses is followed by a 
description of the processes by which the support group was established.

Results Some of the functions that the group has come to provide and recurring themes are highlighted along with a more theoretical understanding of the nature of groups within institutions.

Clinical implications Support groups can help prevent isolation and demoralisation.

Staff support groups have come to be seen as an important way in which morale can be maintained and the risk of burnout reduced among professionals caring for patients (Rabinowitz et al, 1996; Roberts, 1997). Nurses on oncology wards are exposed to the extremes of human suffering and repeated confrontations with death. They experience high levels of psychological stress (McAbee, 1991; Molassiotis \& Van den Akker, 1995) and score higher norms in levels of despair, social isolation and somatisation (Feldstein \& Gemma, 1995). Despite this, several studies have suggested that oncology nurses actually suffer lower levels of "burnout" than other nurses (Papadetou et al, 1994; Molassiotis \& Haberman, 1996) and that this may be a recent trend owing to an increased awareness of stress within this nursing group and the provision of organisational support (Vachon, 1995). Personality characteristics also are seen to be important in predicting the variability of burnout experienced in oncology nurses (Papadetou et al, 1994). There may be personality factors that allow oncology nurses to modify their philosophy and attitude to life in ways that enhance their ability to find their work meaningful (Beck-Friis et al, 1991). The quality of relationship that oncology nurses establish with their patients has been shown to relate to job satisfaction (Peteet et al, 1992) as has the degree of ward cohesiveness and inter-nurse conflict (Beierholm et al, 1989). There is seldom opportunity for nurses to share the grief they experience when patients die; through habitual denial a store of considerable grief is created which often finds expression at a later date (Stowers, 1983). It has been shown that burnout scores correlate with a lack of psychological support in the work place and also with the number of deaths on a unit (Bram \& Katz, 1989).

How this particular staff support group came into being will be first described.

\section{Why, when and how}

Not long after arriving in a psychotherapy department for my 12-month placement, the sister from one of the oncology wards in the neighbouring district hospital rang requesting a facilitator to run a staff support group. Herein lies an important first key to unlocking one of the many barriers that bar the way to a successful group: who wants it and whose group is it? This is not to say that ambivalence and issues of ownership do not recur but that for the group to come to occupy an important part of the ward's week, a motivating and supportive ally (such as ward manager/sister) is essential. In this way, the group comes to be wanted and valued and is seen as belonging to the ward, rather than being an intrusive extension of the psychotherapy or psychology department.

The second important key is the quality of relationship with the ward manager/sister that needs to be attended to and maintained. In this instance, a working relationship has evolved over time which is mutually supportive; the sister/ manager does not attend the weekly group but I make a point of establishing the briefest of contacts with her before and again after each meeting. The ward sister and I meet regularly every two months for 30-45 minutes in a quiet room off the ward. Details of group content and processes are not discussed but general themes and how the ward is functioning are. It is an opportunity for the sister/manager to air her concerns and it also appears to be important to ward staff, with obvious parental overtones, that sister and therapist have a relationship of their own. This adds to the sense of security of the group's place within the week and of containment.

Occasionally fears are expressed within the group that I will be reporting on individual members during these meetings which sometimes results in a descent into a powerless/ helpless feeling. Paradoxically, once this fear has been given voice to, there often follows a swing towards empowerment during which members realistically question whether authority needs to result in a stifling of initiative and whether or not, by acting together, there is not after all the possibility for change.

The third important prerequisite for facilitating such a group is regular supervision from a group therapist with experience of facilitating staff groups. I meet with my supervisor, a group analytic psychotherapist, fortnightly for $50 \mathrm{~min}$ utes; this has been invaluable in providing me with not only a framework within which to understand the group but also by giving me encouragement and by reminding me when I have needed reminding that such groups, despite their sometimes mundane and humdrum outer appearances, are finely-wrought creative processes whose significance for individual members is not always readily apparent.

The group meets for an hour every week on a weekday afternoon in the patients' sitting room at the end of the ward. I am there early to set the chairs in a circle, open the windows, turn off the television and occasionally to ask patients relatives to wait in another sitting area. I then go to the nurses' station, greet the nursing staff and return to the group room to wait. My routine is the same each week, although not rigidly so. At 
the end of each session we re-arrange the room to a sitting room and walk back to the nurses' station together before I leave the ward. The usual size of the group is four nurses, sometimes five, very rarely two. Nurses work a 12-hour shift (7.30 am-7.30 pm) and it is more usual than not for them to reach the afternoon without having had either a coffee or lunch break. Only on two occasions has the ward been so busy that the group could not take place as the minimum of two nurses could not be made available. There has been a tendency in recent months for more nurses to attend (four or five rather than three or four) which may not reflect staffing levels so much as a shift in priorities. One of the themes I will discuss later is that of making space and in so doing setting limits and creating a boundary. Below I describe what I have come to view as the main functions of the group.

\section{The group as an in-between space}

The group takes place in an in-between space that is not home and is not the ward. This allows members to 'play' among themselves and to bring healthy/nurturing aspects of home life into an easier contact with their professional/work selves. Fears of the opposite aspect are often expressed in terms of contamination, either emotional or physical (i.e. that of taking the stress and sadness of work home, or of developing a cancer through being exposed to radiation/ chemotherapy on the ward). Group talk when non-focused shifts from non-ward matters: shopping, holidays, parties, to important ward business: who is off sick, duty rotas, how Mrs Soand-so's chemotherapy is going, how Mr X died. This intermingling and sometimes rapidly changing mix of home and work has an anxietylowering function by interfusing the ward (harsh, death-filled, outer reality) with aspects of mother (nurturing, protective, safe). How successful this is for each member would depend upon their own particular home circumstances past and present; if this is not favourable the negative effects will be militated against by the positive home/ mother experiences of other members.

Humour is used frequently. A kind of raucous, black humour often follows after the group has touched some deeply-felt concern (i.e. the discussion of some painful situation is followed by an intense, shared silence which is then followed by a joke). These often unpredictable outbursts of humour, partly displacement, partly denial, appear to have value in maintaining balance within the group; they are a gauge showing just how much pain and anxiety the group can contain in any session. They bring about a sudden shift (back to the surface). A comment such as "some things are just far too important to be taken seriously" is one way of keeping the channels open such that the humour does not fragment communication but rather the change of level can be acknowledged and the direction maintained. The analogy of depth and direction is useful; there is time for surface work which can be very important, although it may seem directionless, on the other hand too much time at depth is claustrophobic and frightening. Somewhere in between. with freely-flowing movement up and down, is when the group is using itself optimally. The group as an in-between space is a place to relax into, to shed the shoulds and shouldn'ts and to enjoy.

\section{The group as repository of ward memory}

The ward is in a constant state of grieving and is at different stages of the grieving process all of the time. There is numbness and disbelief, anger, survivor guilt, sadness and despair. And there is acceptance. Most of the emotional states pass unacknowledged on the ward but find expression within the group through the regular act of remembering patients who have died. Either out of a period of silence or in the midst of a busy exchange, a patient who has died will be remembered: "Do you remember Mrs $Y$ who died when you were on duty?". The trigger for the memory could be an association such as seeing the deceased's partner or the configuration of nurses in the group being the same as those on duty when the patient died, or sometimes a dream: "I dreamt of that patient who died in C bay last month". It appears always important to remember the patient's name which involves the group in lengthy discussion with each member mentally scanning back through all those who have died. When a patient has been remembered, there will follow another and usually another, all momentarily returned to life, dressed in their night clothes, surrounded by their families. Expression of feelings has become less muted as the group has grown in trust. There are difficult-to-voice feelings of anger with patients who have died and anger with their relatives; angry at being made to feel helpless to either stop the death or to end the suffering. Anger at the unbearableness of being projected into by upset/ angry relatives, to be made to feel the unfairness of it all. All these painfully find expression and then sink back into the group's collective memory, to return at seemingly regular intervals as part of an unending flow.

\section{The group as modifier of guilt}

Related to the discussion above, there appears to be a powerful element of guilt in the ward milieu, which is a recurring theme in different guises within the group. I believe this is a many-layered phenomenon with at least three interacting levels: firstly nurses unconsciously come to feel 
responsible for their patients' suffering as I will describe. Secondly, in responding to the continual demands and neediness of their patients natural feelings of frustration, anger and hatred usually well re-ressed break through into awareness with accompanying feelings of failure and guilt. Thirdly, and related to the above, these feelings can reactivate early fantasy memories from childhood creating a profoundly disabling sense of guilt. These latter two hypothesised elements are elaborated on later.

The first layer seems to come about in part from nurses over-empathising with their patients; offerings of sympathy "I'm sorry" essentially healthy and supportive gestures run very close to and are experienced as an apology "it's my fault". This, along with relatives' and patients' powerful defensive need to blame somebody in an effort to restore meaning. paves the way for nurses to carry considerable guilt, not only for patients not getting better but also, and more irrationally, for them getting cancer in the first place. How to maintain the sympathy but not to take the responsibility has become an important issue which is addressed in part by the structure and constraints which the group itself imposes; a limit or a boundary is created by the group's presence which interrupts work. Nurses need to allocate their time strictly to the different tasks they are involved with as the time for the group approaches. They have to explain to patients relatives that they will return after the group. This rationing of themselves by making themselves not available to patients created considerable conflicts early in the year. As the year progressed, the nurses appear to have harnessed the necessity for maintaining the group's boundary to their advantage. They have learned to balance their own needs against those of their patients which has helped to lessen the tendency to over-empathise. Paradoxically, the guilt they strongly voiced at "abandoning the ward" to attend the group, like a potentised remedy has helped assuage the far deeper 'responsibility' guilt. The outer structure of the group appears to have strengthened the development of a corresponding inner boundary which allows the healthy separation of nurses' needs and patients' needs, sympathy but not responsibility. The fact of the group's being conducted within the ward's boundaries and even displacing some patients from the sitting room I believe has offered a form of modelling of non-attachment allowing staff to maintain a more secure, emotionally protective hold on their professionalism.

\section{The group as an anchor}

In a general sense, the regularity of the group provides a reliable fixture from which members can orientate themselves and take bearings. It is a place of stillness away from the hectic unpredictability of the ward. It helps provide the 'middle ground' and reintroduces a sense of balance. Often it is the first opportunity for the nurses to eat since starting their shift. The theme of food is prominent and is sometimes discussed in lavish excess. The symbolic nurturing/nourishing function of the group is prominent pitted as it is against a depleting, evacuating, draining aspect of the ward. The group carries the explicit message of 'being valued' to its members and the ward. In addition I believe the group has come to operate as the guardian of a certain model that represents the ward's unwritten and evolving philosophy of working where hope and idealism become balanced by a morbid realism rather than descending into cynicism and despair: where the unreasonableness of suffering, the reality of death and the limits of medical help come first and painfully to be acknowledged and then accepted. The presence of the group within the working environment, week in, week out, has visibly conferred an element of support and is now felt to be an important structure that underpins the ward's work. This is true even for the nurses who do not attend in any particular week; it is the fact of the group's existence that seems important, that a process has been started that is both contained and containing.

\section{Conclusions}

One of the great strengths of working in groups is that, according to the ability of the facilitator, the group can be both supportive and analytic at the same time for different members, i.e. Yalom's (1975) well known curative factors such as universality, interpersonal learning, altruism etc. will be operating but so will the analytic process. Support groups offer "Ego training in action" (Foulkes, 1948), even though they are not therapy groups. While keeping the focus on ward issues and related matters, I keep an awareness of group processes and comment upon them as long as they are helpful to the group's task. However, I have found it important to keep in mind that members have not undertaken to be part of a therapy group as such.

In addition to the literature on 'burnout' in nurses there is a more theoretical analytic understanding which has been well described by Menzies (1988) and Hinshelwood (1987) and others. Just as every individual develops techniques for defending him/herself against feelings of anxiety, it has been suggested that the same is true for institutions, hospitals on a large scale, wards on a smaller scale (De Board, 1978). This would account for the resistance that is often met whenever staff support groups try to become established. The institution has great difficulties 
in achieving social change, even the seemingly small change as represented by a support group; this is linked to difficulties in tolerating the anxieties that are released as social defences are re-structured. Over-reliance on defence mechanisms are primary causes of both personal ineffectiveness and institutional malfunctioning. Authentic and creative responses to situations become diminished in proportion to the amount of mental energy that is invested in maintaining defence mechanisms. On an oncology ward there are palpably high levels of external anxiety which need containment; in addition there is a source of internally generated anxiety which can be understood from an object relations theory perspective:

The work situation arouses very strong and mixed feelings in the nurse: pity, compassion and love: guilt and anxiety: hatred and resentment of the patients who arouse these strong feelings; envy of the care given to the patient. (Menzies, 1988)

It has been suggested that this mix of conflictual feelings activates feelings associated with fantasy situations originating in earliest infancy when the overlapping of aggressive and reparative impulses, along with the separation of good and bad objects, generated considerable anxiety. By projecting these re-activated fantasies onto the ward, the objective work situation comes to symbolise the fantasy situation. If the anxiety generated by the objective work situation can be mastered, there is an opportunity for these deeply unconscious anxiety-creating fantasies to be modified. Segal (1957) emphasised how for such symbolic representation to be effective the symbol must represent the fantasy object and not be equated with it;

If, for any reason, the symbol and the fantasy object become almost or completely equated, the anxieties aroused by the fantasy object are aroused in full intensity by the symbolic object. The symbol then ceases to perform its function in containing and modifying anxiety.

Staff support groups, I suggest, help prevent the collapse of symbolic representation through the creation of an 'in-between space' as described earlier and through the use of metaphor where members are encouraged to step back and reflect on the ward and their work with an 'as if quality. This containment and mastery of external anxiety through the group's work corresponds to the individual realignment of internal objects leading to greater integration and sense of wholeness.

In Institutes and How to Survive Them. Skynner (1989) refers to networks operating as safety nets. However intra-psychic processes come to have a bearing on our work, as they must, the simple fact of feeling securer and functioning better at work when we feel part of an under- standing and supportive network should not be overlooked. Support groups can help join the threads of such a network together and in so doing prevent isolation and demoralisation. They can help members feel more wholehearted at work and increase job satisfaction. In addition they can be the source of much wisdom and, so long as they do not set out to do so, can promote personal growth.

\section{References}

Beck-Fris, B., STRang, P. \& SuOden, P. (1991) Work stress and job satisfaction in hospital based home care. Journal of Palliative Care, 7, 15-21.

BEIERHOLM, M. TISEUUS, I. \& EK, A.C. (1989) The risk of nurses of developing burnout syndrome. Scandinavian Journal of Caring Sciences, 3, 13-18.

BRAM, P. \& KATZ, L. (1989) A study of burnout in nurses working in hospitals and oncology settings. Oncology Nurses Forum, 16, 285-290.

DE BOARD, R. (1978) The Psychoanalysis of Organizations. London: Tavistock.

Feldstein, M. A. \& Gemma, P. B. (1995) Oncology nurses and chronic compounded grief. Cancer Nursing. 18. 228-236.

Foulkes, S. H. (1948) An Introduction to Group-Analytic Psychotherapy. London: Heinemann. Reprinted 1983. London: Karnac.

HiNSHELWOOD, R. D. (1987) What Happens in Groups. London: Free Association Books.

MCABEE, R. (1991) Occupational stress and burnout in the nursing profession: a model for prevention. AAOHN Journal, 30, 568-575.

Menzies, I. E. P. (1988) Containing Anxiety in Institutions. London: Free Association Books.

MOLASSIOTIS, A. \& VAN DEN AKKER, O. B. A. (1995) Psychological stress in nursing and medical staff on bone marrow transplant units. Bone Marrow Transplantation, 15, 449-454.

- \& HABERMAN. M. (1996) Evaluation of burnout and job satisfaction in marrow transplant nurses. Cancer Nursing, 19, 360-367.

Papadatou, D.. ANAGNOStopoulos, F. \& MonOS. D. (1994) Factors contributing to the development of burnout in oncology nursing. British Journal of Medical Psychology. 67. 187-199.

Peteet, J. R., Ross, D. M., Medeiros, C., et al (1992) Relationships with patients in oncology: can a clinician be a friend? Psychiatry. 55, 223-229.

RABINOWITZ, S., KUSHNIR, T. \& RIBAK, J. (1966) Preventing burnout: Increasing self-efficacy in primary care nurses in a Balint group. AAOHN Journal, 44, 29-32.

ROBERTS, G. A. (1997) Prevention of burnout. Advances in Psychiatric Treatment, 3, 282-289.

SEGAL, H. (1957) Notes on symbol formation. International Journal of Psychological Analysis, 38, 391-397.

SKYNNER, R. (1989) Institutes and How to Survive Them. London: Methuen. Reprinted 1991, London: Routledge.

STOWERS, S. (1983) Nurses cry too, being exposed to death and loss. How do we deal with our own grief. Nurse Management, 14, 63-64.

VACHON, M. L. S. (1995) Staff stress in hospice/palliative care: A review. Palliative Medicine, 9, 91-122.

YALOM, I. D. (1975) The Theory and Practice of Group Psychotherapy (2nd edn). New York: Basic Books.

Charles Montgomery, Senior Registrar in Psychiatry, Wonford House Hospital, Dryden Road, Wonford, Exeter EX2 5AF 